\title{
Problems and Prospects of Livestock in Uzbekistan
}

\author{
Salimova Noila* \\ Student of Veterinary medicine, Samarkand, Uzbekistan

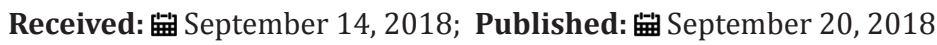 \\ *Corresponding author: Salimova Noila, Student of Veterinary medicine, Samarkand, Uzbekistan
}

\section{Abstract}

The present article presents the role of fodder production in cattle husbandry sector, the theoretical L practical aspects of the fodder mass, as well as determined the impact of fodder to cattle breeding and the ways of its estimation. Besides, there were worked out the recommendations and suggestions on supplying the cattle husbandry sector with fodder in our country conditions.

Keywords: Cattle husbandry; Feed base; Cattle productivity; Mixeolfood roughage; Fertile cattle

\section{Introduction}

In the condition of market economy, the developing level of animal husbandry sector is identified by several economic factors. Some other factors result in high development rate of the sector. But, the lack of these main factors impedes possibility of expected positive results. Particularly, in development of animal husbandry one of generally accepted and the most important factors is strengthening feed base of the sector. But it should be noted that, the points like increasing proficiency of livestock, improving product quality and declining the product cost price are closely linked with the issues of improving livestock breed, intensification of through bred animals and developing levels of veterinary services. The chances of fully usage of biological thoroughbred cattle can be obtained through feeding the livestock with fodder of good quality [1]. The biological purity of cattle of any breed is achieved only by proper feeding condition rich in sufficiently nutritional content and all components. Today in our republic the manufacturing of cattle products is mainly under control of private sector. At present days the tasks for further development of cattle purity and heritability peculiarities are required to be implemented widely.

However, private farming units by its size may cause difficulties for operation of breeding with heritability on industry basis. In its turn the possibility of radical increase in demand for dairy and meat products is limited, in the republic where these products are in wide demand. When we studied the content of daily diet ration of the dairy stock in farming units, our monographical observations showed that in some regions rich feeding value of cattle diet ration does not correspond with principles of cattle feeding. Apparently, roughage (mostly grain straw) makes the main part of diet ration even if the cattle is bred for milk and meat in farming units. And this case is one of the factors that can decrease productivity of livestock farming. Moreover, there is another organizational-economical problem in animal husbandry sector of our republic which is not viewed thoroughly. Sometimes farming units' managers or farmers say that they have some numbers of cattle and in order to increase the herd quantity and to feed them daily they don't have enough land for growing and producing feed. It is true, of course, because effectively and intensively used agricultural land areas are limited not only in our country but also in the world [2]. Shortage of effectively used land areas in agriculture is an ancient and long-life problem of human. This problem may increase the two growing of population and demand for food in future. But there is another side of the problem which must be considered. And how can it be viewed?

There are possibilities of land areas for animal husbandry sector where feed is grown and harvested, or stock is reared in each household farm, district or region, and possibilities for purchasing feedstock exist. These possibilities are seemed to be predicted. It means that feed production volume can be considered beforehand in each farm and, it doesn't require deep knowledge on farming. Furthermore, in regional and even in republican level these points are predicted on counting basis. Consequently, possible points can predetermine the amount of feed production areas (separate farming units, farms, district sand regions). At the same time the required feed amount per head is identified basing on norms and considering pure-brad (productivity) peculiarities of livestock. In this way the quantity of cattle is counted to be reared on the farm. Excessive number of stocks over calculation is economically 
unprofitable. Because, shortage of feed, results the waste of productivity of milk and meat. In other words, the feed is used for cattle only to maintain their physiological weight not to increase meat or milk prolificacy [3]. Now we'll see another side of the matter, due to lack of food, stock cannot gain enough weight, as a result prolificacy indication is low in calf producing in recent years. It means that money spent in this sector does not bring profit and is in waste. Low feed supply level reflects in low productivity of cattle. Today increasing milk production capacity is a prior task in our republic. But increase in milk production capacity should be done at the expense of productivity not increasing number of heads of stock.

Meeting the needs of people in our country for milk and dairy products depends on developing measures for farms. Priorities on developing the sector are growing productivity of livestock, creating feed base and improving the quality of veterinary service. The problems in formation of sale system of dairy products made in farming units, difficulties in drawing investments on implementing unwasteful technologies for reprocessing system of milk in rural areas are impeding in development of animal husbandry sector [4]. Therefore, without improving the breed or strengthening fodder base high productivity cannot be obtained. For high productivity it is required to improve regularly the breeds, to work out artificial insemination system of cattle in household, to provide veterinary and zootechnics service system of high quality. Strengthening fodder base of animal husbandry and improving cattle breeds are connected with each other, they cannot be effective separately and they are main factors which serve for one aim. When we follow these factors of development, we can see considerable positive changes in the development of cattle-breeding sector.
In order to maintain positive changes, it is required to keep correspondence of possibilities of producing livestock quantity and their products capacity with possibilities of fodder producing, fodder purchase and sale of cow products. There is no doubt that on stock farms (district, region or economical areas) "planning quantity of cattle heads is done basing on amount of fodder producing". It is fact, and not counter current. Cattle-breeding farms (farming units) usually try to find fodder for cattle, only after increasing number of livestock heads (by purchasing them or keeping for rearing). Although they can find enough fodder, mostly its content is not considered carefully or there is no possibility to find other necessary components to make its content rich in nutrients which are based scientifically. In shortly saying "farmer feeds the cattle with any diet that he can find, but not with proper diet required on scientifical basis". In case of shortage of fodder for current cattle, farmer feeds 2-3 cows with the feed of one cow. According to this, we can say that, high productivity indication is not guaranteed.

\section{Methods of Research}

Hereby we must clarify that there exist two parts of fodder mass required for cattle-breeding by theoretical and practical point of view (Figure1): The first part - it makes fodder mass for maintaining physical state of cattle (conventionally called as "physiological feed"). "Physiological feed" amount usually constitutes 1,0 kg of feed unit per $100 \mathrm{kgs}$ of cattle in a day. The second part - it makes fodder mass for formation of livestock products (conventionally called as "Productive feed"). It is obvious that any reduction in fodder amount firstly occurs at the expense of "productive feed" and directly affects to decrease in prolificacy of the cattle. This rule is of great importance not only in total amount of fodder required for cattle, but also in its component structure.

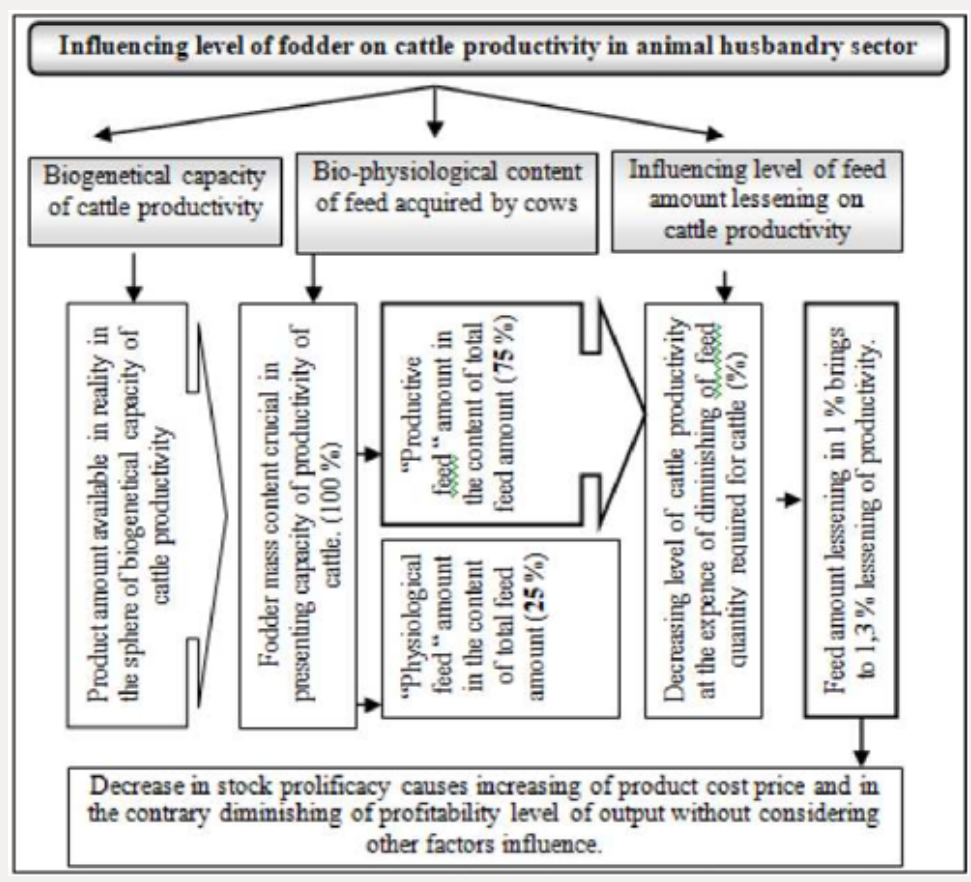

Figure 1: Methods of research. 
Proportionality in feed lessening and productivity in animal husbandry sector [Source: Worked out by author]. For example, 38-42 center feed units are required for a cow which can give 3500-4000 liters of milk. The required feed unit needs to be in the level of scientifically based norms according to organizational structure (according to succulent diet; roughage, mixed forage, micro and macro elements). 32-42 center feed unit can be supplied with mixture of straw and alfalfa hay which is required for dairy stock with milk productivity of $3500 \neg 4000$ liters. In this way the intended productivity is not possible. And its result is obvious in some cases. At the expense of productivity decrease the farmer's money spent in cattle-breeding sector is hardly profitable or may cause a financial loss. Moreover, some farms, especially, farming units don't calculate their profit value comparing the value of material-technical resources spent in livestock-breeding sector with profit amount.

\section{Results and Discussion}

According to our account "productive feed" amount makes $75 \%$ of total feed amount, "physiological feed" makes $25 \%$ of total feed amount. So, there is a direct link between decrease in feed amount required for cattle and in running the cattle productivity down. Decrease in feed amount for 1,3 \% brings on decrease in cattle productivity for $1,3 \%$. It should be stated that feed amount decrease occurs in "productive feed" and it effects productivity also. Therefore, stability and nutrient value should be particularly considered in feeding the stock.

As our monographical observations and calculations show, milk productivity of 1900-2000 liters in present day cattle-breeding is below the norms rate of profit and it causes a financial loss. If we base on our assumed account, output may bring purposed profit to farmer only if milk productivity is over 2500 liters in dairy stockbreeding. Founding on monographical observations we have made a conclusion of theoretical and practical significance as follows: «The causes of regular development of cattle breeding sector of our republic and "moving" livestock breeding sector completely into farming units and farms are closely linked with financial significance of output development on family basis in agricultural sphere».

Family based output in agricultural sphere is durable enough to economic crisis due to less costs comparing to output in hired labor (freelance) used condition in family farms labor payment fund is not available or labor is underestimated. Gross profit of family by setting output has the same economical value with "business profit".

Simply saying, the family farm manager does not give a payment to his or her children and obtains output profit as a property which belongs to all family. This very case enables livestock-breeding to move to family-based farming units and farms, and it is likely to be a reason of regular development of the sector [5]. There is a saying like "experienced cattle-raiser is never in loss", and this is true. Besides it we should always keep in mind our ancestors' saying like "Cow's milk is by its tongue", it means that there is a direct connection between feeding conditions of cattle and productivity. Basing on above-mentioned points the following system is recommended on providing proportionality among possibilities of increasing heads quantity of cows, product output capacity and fodder production, its purchase and sale of products in order to strengthen feed base of livestock breeding branch (Figure 2).

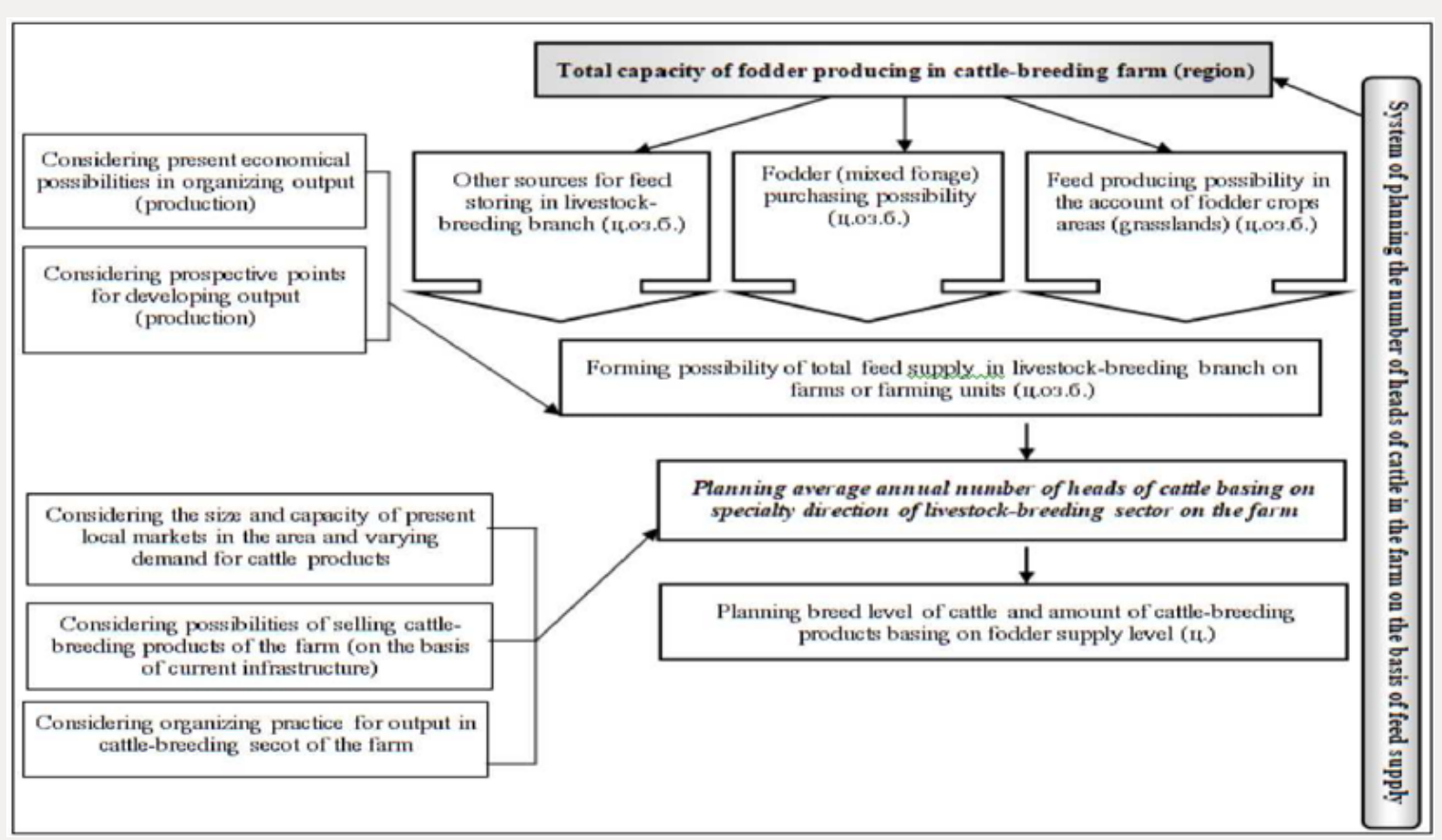

Figure 2: System of planning the number of heads of cattle and product capacity on the basis of fodder supply level. 
In a particular livestock farm (farming unit or farm) or in an area fodder producing possibility is calculated for livestockbreeding sector. Here: FS - feed supply,

$$
F S=C F F+F P+O S
$$

CFF - feed amount harvested from fodder crop fields, (mo3.6.);

FP - feed purchasing possibility of the farm, (mo3.6.);

OS - other sources of feed storing (mo3.6.).

For livestock sector in the range of calculated possibility of fodder producing it can be defined that how many numbers of cattle might be bred on the farm (in particular region) (C). Here:

$$
c=\frac{O T}{S N} * P C
$$

SN - scientific norm of feed annually required for cattle of particular productivity according to definite specialty direction (mo3.6.);

PC - use coefficient of capacity of biogenetical productivity of thoroughbred cattle.

Firstly, the size and capacity of local markets for cattle products are detected or required to calculate possibilities of cattle products sale in other regional markets. Moreover, considered prediction on livestock-breeding future and its long-life activity.

\section{Conclusions}

Besides it, the amount of mixture of leguminous crops such as soy-bean, corn and others which serve to enrich the content of cattle diet with protein should be increased on the farms.

a. In application of results and achievements from advanced experiences, science and technics into cattle-breeding sector, it is required to care not only about breeding system and artificial insemination system, but also consider creation of feed supply system which forms real possibilities for using the feeding ration [6].

b. If we rely on experiences of countries with advanced livestock-breeding sector, we found out that one of important basis of developing cattle-breeding in the republic is to improve the system of mixed fodder output.

c. It is required to expand the main and rotatory corn crop areas in order to increase amount of corn in the content of cattle feed, mainly in mixed fodder, because corn (maize) is of high nutrient value;

d. Implementation of mechanisms are to be developed for economically and legally supporting of markets and market branches specialized in selling mixed forage, roughage and other kinds of feed on the basis of private entrepreneurship in the regions where livestock-breeding is developed;

e. It is necessary to find possibilities of improving composition of crop areas on the farms, to work out measures for increasing amount of fodder crops for $20-25 \%$ and also to grow fodder crops as a rotatory crop in the irrigated areas freed from grain crops. In order to fulfill this task, it is required to implement additional supply of water, fertilizers and fuel-oil materials to farms;

f. By changing the crop fields of the farms where cotton and grain crops are in regular low yield into fodder crops field, feed base of stock-breeding sector should be fortified and consequently it leads increase in soil prolificacy;

g. There is a demand for privileged, long-term credits to buy tillage technics and fodder crop harvesting technics on farms and farming units, for mini-workshops to produce mixed fodder;

h. It is important to develop private enterprises which provides fodder supply and other resource supply for smallsized stock farms and farming units situated far from markets;

i. Practical projects and innovative projects are to be supported on producing micro and macro elements which are considered to be necessary parts of cattle feed and mixed fodder on industry basis and enrichment of feed content with local raw materials by common methods.

In order to fortify feed base of stock-breeding sector the followings are to be implemented: to create agrotechnical methods for cultivation of feed crops basing on scientifically based system and to form scientific supply for producing prolific fodder crops.

\section{References}

1. Khushmatov N, Rakhimova G (2008) The mapping problems of developing the cattle-breeding sphere in market economy condition. Uzbekistan economical reference book 12: 13-14.

2. Khushmatov N, Abdullaeva S (2013) Production, reprocessing and realization of cattle husbandry production, system of factors impacting on economic relations modernization. Scientific-practical recommendati' ons. UzBIIITI -Tashkent p. 20.

3. Fayzullaeva T, Khushmatov N (2009) The juridical basis of farming development. “Agroscience” Uzbekistan's agriculture journal's scientific enclosure 11: 65-66.

4. Khushmatov N, Fayzullaeva T, Rakhimova G (2008) The cattle-breeding: the economical issues or the world experience. Uzbekistan's agriculture journal 8: 34-35.

5. Khushmatov N, Kuchchiev U (2012) The economical importance of cattle-breeding sphere, regularities and main conditions. Book-Tashkent p. 34. 
(c) This work is licensed under Creative

To Submit Your Article Click Here: Submit Article

DOI: $10.32474 /$ PRJFGS.2018.02.000139

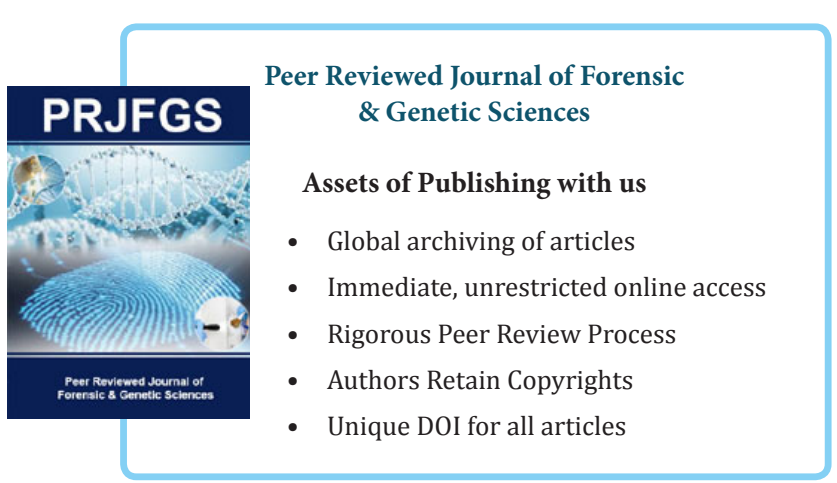

